\title{
AS PERSPECTIVAS E DESAFIOS DO PLURALISMO JURÍDICO NA AMÉRICA LATINA
}

\author{
THE PERSPECTIVES AND CHALLENGES OF LEGAL PLURALISM \\ IN LATIN AMERICA
}

\begin{abstract}
Janaina Helena de Freitas
Mestre em Direito pela Universidade Federal de Alagoas. Doutoranda em Direito e Sociologia pela Universidade Federal Fluminense. E-mail: janaina.helena@gmail.com

\author{
Mestre e Doutora pela Universidade Federal de Pernambuco. \\ Professora Adjunta da Universidade Federal de Alagoas. \\ E-mail: gracagurgel@uol.com.br
}

Maria da Graça Marques Gurgel
\end{abstract}

RESUMO: O pluralismo jurídico na América Latina, tema deste escrito, possui uma roupagem diferente e que necessita ser estudada de maneira independente das correntes europeias. Por outro lado, o atual momento da sociedade demonstra desafios que precisam considerar de maneira ampla o indivíduo dentro de variados coletivos, exemplificadamente: movimentos sociais de periferia, indígenas e de outras tantas populações que lutam por reconhecimentos e direitos. Dessa forma, o presente trabalho possui o objetivo de avaliar como o pluralismo jurídico ocorre na América Latina, especialmente nos países em que suas Constituições expressa como um subprincípio do Estado Democrático de Direito, na expectativa de analisar o panorama atual da efetividade desse princípio onde ele se manifesta expressamente e desaguando em uma análise do panorama brasileiro.

PALAVRAS-CHAVE: Pluralismo Jurídico; América Latina, desafios.

ABSTRACT: Legal pluralism in Latin America has a different guise and needs to be studied independently from European currents. On the other hand, the current moment in society shows challenges that need to consider the individual in a wide range of social contexts: social movements, periphery, indigenous, etc. Consequently, the present work has the objective to evaluate how legal pluralism occurs in Latin America, especially in countries the Constitucions expressed as a subprinciple of the Democractic Rule of Law, int the hope of analyzing the current panorama of the effectiveness of this principle where it manifests itself and results in an analysis of the Brazilian panorama.

KEYWORDS: Legal pluralism; Latin America, challenges.

\section{INTRODUÇÃO}

A Constituição da República de 1988 inovou e previu um vasto catálogo de direitos fundamentais; a despeito disso, há um imensurável número de indivíduos que não detêm as 
mínimas condições de subsistência. Por outro lado, igualmente há uma considerável fatia de relações sociais que não são albergadas pelo Direito Estatal, ou seja, aquele produzido pelas fontes legislativas oficiais e operacionalizado pelo Poder Judiciário em sua pragmática.

O Estado, ao conduzir a sociedade sob seu monopólio, mediante uma atuação jurídica formalista, cerimonial e estritamente positivista dos Poderes constituídos, não atende aos anseios sociais muitas vezes não sendo promotor de pacificação dos conflitos que atingem principalmente as pessoas que vivem em contexto periférico.

Dada a ineficiência do alcance das leis e o afastamento do Poder Judiciário de grande parcela da sociedade que não consegue levar seus pleitos a uma via de resolução de conflito oficial, seja em virtude de desinformação sobre seus direitos, seja por dificuldade de obter a assistência judiciária, por razões financeiras, ou, ainda pelo descrédito ou morosidade do judiciário, faz-se necessário uma ressignificação de outras formas de promoção do Direito. O monismo jurídico encontra-se esgotado, impondo-se a consideração da inserção de outras práticas sociais na produção da vontade social, política e jurídica.

Neste contexto, o pluralismo jurídico surgiu como alternativa ao cenário de ineficiência e esgotamento do modelo exclusivamente estatal de produção e efetivação normativa de direitos, especialmente por aproximar o Direito da realidade social. A teoria ganhou grande repercussão no Brasil após a década de 80, impulsionada pela tese de doutorado apresentada na Universidade de Yale pelo sociólogo português Boaventura de Sousa Santos. Posteriormente, surgiu a teoria de Antônio Carlos Wolkmer, denominada pluralismo jurídico comunitário, tendo como justificativa os novos sujeitos coletivos emanados do seio da sociedade, por exemplo, os povos primitivos em prol de sua autossubsistência, trabalhadores, pescadores e os movimentos sociais, como fontes de produção de normas jurídicas.

Quando se rompem as barreiras internas e enxerga-se o contexto no qual o Brasil se insere, verificam-se em países latino-americanos iniciativas pluralistas aparentemente mais avançadas, especialmente por trazerem o reconhecimento em suas próprias Constituições. O pluralismo que prevalece na América Latina é o de cunho indígena e os de comunidades campesinas nativas, como tentativa de afastamento do papel inferior de colonizado, introduzido via colonização europeia.

Apesar de que é propício comentar o ressurgimento de possibilidades de novas categorias plurais nascidas, como sempre, dos movimentos de lutas e resistências que aparecem como novos direitos requisitados por esses segmentos que buscam intervenção ora estatal, ora social. Não se pode ignorar no momento da pandemia global do Covid-19, que esse fenômeno traz à tona novos direitos fundamentais como da provisão de renda temporária mínima, cuja fundamentalidade advém da própria dignidade humana ameaçada de sua sobrevivência dado as circunstâncias e fatores que envolvem as medidas ultracapitalistas de espoliação da força de trabalho, danos irreversíveis ao meio ambiente, competições entre Estados Hegemônicos e outros tantos aspectos que merecem ser referidos ainda que este artigo não comporte a atualização necessária 
Neste artigo, portanto o que se pontua é que, a despeito da alteração de circunstâncias havidas como avanço neste processo, ainda assim, há um problema a se visualizar: o pluralismo jurídico se mantém, mesmo com os retrocessos atuais no Brasil e em outros Estados latinoamericanos, repousando aqui a hipótese de nossa pesquisa.

Dessa forma, no tópico inicial faremos uma incursão pelos antecedentes históricos do pluralismo jurídico. Em segundo momento, iremos trazer a reflexão sobre o papel do pluralismo jurídico como contraponto à unicidade do Direito Estatal. No terceiro tópico, traçaremos o pluralismo jurídico na América Latina, trazendo os principais aspectos e aprofundando nos países que adotam o pluralismo jurídico formalmente na Constituição Federal. Por fim, o presente trabalho será concluído com a breve experiência brasileira em relação ao tema, que subjaz desde o próprio título.

A técnica utilizada para a abordagem será a pesquisa bibliográfica, nacional e estrangeira, com atenção a autores latino-americanos, ao lado de uma breve análise de dados retirados de fontes oficiais. Inicialmente, revisando as ideias principais do pluralismo jurídico no seu processo histórico. E, ao final, de modo incidental à realidade vigente, mostrando a sua possível resiliência prática com os acontecimentos críticos que o Mundo passa, mormente os países periféricos e os seus habitantes mais vulneráveis.

Para isso, ressaltamos que serão traçadas noções históricas e conceituais do pluralismo jurídico, remontando ao período feudal, bem como se enfatizará a superação da falsa ideia de pluralismo jurídico como contraponto ao direito oficial. Também será abordado o pluralismo jurídico latino-americano, suas principais nuances, características e desafios. Por fim, passar-se-á a um estudo sobre o pluralismo jurídico no Brasil. Neste, serão desenvolvidos suas principais teorias e autores, com ênfase enfoque na contribuição de Wolkmer e no estudo pioneiro de Boaventura de Sousa Santos.

\section{UMA INCURSÃO NOS ANTECEDENTES HISTÓRICOS DO PLURALISMO}

O pluralismo jurídico tem raízes históricas que remontam à Antiguidade e tem ligação com a intensa circulação do homem naquela época. A existência de diversos grupos espalhados e circulando pelo mundo trazia como consequência a ausência de um resultado satisfatório em relação as regulações jurídicas existentes. Dessa forma, a experiência demonstrou que era mais funcional e proporcionava maiores resultados a regulamentação originada do centro de cada comunidade, sobremodo em virtude das peculiaridades, anseios, costumes, tradições e hierarquia de cada local ${ }^{1}$.

A Idade Média foi um momento histórico bem marcante para a propagação do pluralismo jurídico. No Império Romano ocorreu a consolidação de institutos que influenciaram

1 Não se pretende neste trabalho destrinçar a origem do pluralismo em todas suas acepções; não se nega a existência de manifestações de pluralismo nos gregos e em outros povos. Para uma compreensão aprofundada do assunto, sua origem e suas ligações além do pluralismo jurídico, recomenda-se a leitura de WOLKMER, Antônio Carlos. Pluralismo Jurídico: fundamentos de uma nova cultura no direito. $4^{\text {a }}$ edição. São Paulo: Saraiva, 2015. 
sobremaneira o Direito moderno, sem impedir a convivência com outras manifestações jurídicas. O pluralismo jurídico romano baseia-se em duas importantes questões: a primeira é o fato de que os romanos não impuserem de forma rígida seu ordenamento jurídico às populações conquistadas, o que permitiu a existência de regras jurídicas locais em conjunto com as romanas. O segundo, conforme pesquisa de Eugen Ehrlich, é que os próprios romanos conheciam e utilizavam fontes de ordenamentos jurídicos de origem não estatal, o costume e a convicção popular (WOLKMER, 2015, p. 199-200).

Diversas foram as transformações ocasionadas depois do esgotamento do modelo feudal e de sua passagem para o modelo mercantil, base do capitalismo e início do modelo que se conhece hoje. As relações baseadas na servidão e trabalho artesanal cederam espaço para um sistema de produção assalariado, estruturado em manufatura e na posterior produção em série ${ }^{2}$. Estes foram os passos iniciais para que o capitalismo se disseminasse pela Europa, alterando a estrutura política e jurídica da sociedade 3 .

A organização e a consciência de classe não nasceram com homogeneidade; em determinados lugares os trabalhadores se organizaram de melhor forma que em outros. Os trabalhadores europeus mais pobres não detinham organização e liderança fortes o suficiente para a criação de uma alternativa política com olhar voltado para o social; tampouco havia uma organização ideológica solidamente desenvolvida no que tange a sindicatos; quando ocorria, era restrita a poucos milhares de membros (HOBSBAWM, 2007, p. 44-45).

A afirmação do capitalismo veio acompanhada da ascensão burguesa como classe, crescimento este que se deu nos campos social, econômico e político. Estes novos atores eram bem organizados como categoria, permeados por valores da propriedade privada, divisão social do trabalho e pela busca do lucro, imbuídos de valores individualistas. A burguesia pertencia, naquela época, à classe intermediária, entre os nobres e a Igreja - possuidores de poderio econômico e político - e as classes sociais mais populares eram desprovidas de poder, dinheiro e influência política (WOLKMER, 2015, p. 33-34).

$\mathrm{Na}$ atualidade muito se discute acerca do fato de a produção jurídica legislativa e judiciária ser simpática às necessidades do mercado; isso não é novidade. Desde a passagem do feudalismo ao mercantilismo o Direito foi se moldando para se adequar às necessidades e às novas demandas econômicas. Dessas categorias e classes subjacentes. Daí a dificuldade do positivismo com o discurso de neutralidade jurídica ser uma contradição sempre confrontada por teorias críticas.

2 “A economia capitalista moderna é um imenso cosmos no qual o indivíduo nasce, e que se lhe afigura, ao menos como indivíduo, como uma ordem de coisas inalterável, na qual ele tem de viver. Ela força o indivíduo, à medida que ele esteja envolvido no sistema de relações de mercado, a se conformar às regras de comportamento capitalistas. $\mathrm{O}$ fabricante que se opuser por longo tempo a essas normas será inevitavelmente eliminado do cenário econômico, tanto quanto um trabalhador que não possa ou não queira se adaptar às regras será jogado na rua, sem emprego. Assim, pois, o capitalismo atual, que veio para dominar a vida econômica, educa e seleciona os sujeitos de quem precisa, mediante o processo de sobrevivência econômica do mais apto." (WEBER, 2003, p. 50).

3 Na Antiguidade surgiram as primeiras experiências na tentativa de se unificar o Direito. O Direito babilônico, por exemplo, reuniu diversos regulamentos jurídico-sociais no Código de Hamurábi, verificando-se um forte componente de influência religiosa. Neste sentido, importante salientar que o elemento teleológico, assim como a moral e a política, misturava-se com o Direito. (MALISKA, 2009, p. 22). 
As perspectivas e desafios do pluralismo jurídico na América Latina

\section{O PLURALISMO JURÍDICO COMO CONTRAPONTO À UNICIDADE DO DIREITO ESTATAL}

A sociedade encontra-se em constante transformação; o mundo moderno se movimenta diariamente, inserindo novos contextos e demandas. O sistema capitalista, em conjunto com a modernidade e a globalização, provocou profundas transformações na sociedade, estabelecendo esses três fatores como essenciais para determinar como o indivíduo se insere no atual momento da sociedade. Importante observação é que o capitalismo, modernidade e a globalização são discursos que emanam do sistema capitalista em razão de suas próprias crises. Ou seja, para cada estrutura capitalista em crise, o capitalismo cria suas doutrinas políticas produzindo e assegurando sua autorreprodução.

O termo modernização, muito utilizado na sociologia do desenvolvimento, indica os efeitos do desenvolvimento econômico sobre as estruturas sociais e os valores tradicionais. Também é utilizado para indicar etapas do desenvolvimento baseadas na industrialização e na expansão da ciência e da tecnologia. Avançando para a pós-modernização - estágio atual da sociedade segundo parte dos cientistas sociais -, é possível elaborar um perfil detalhado de processos sociais e mudanças estruturais. O termo sugeriu um processo de implementação gradual, em vez de uma ordem completamente desenvolvida (FEATHERSTONE, 1990, p. 23-24).

A globalização trouxe consigo promessas de um mundo mais conectado e cheio de oportunidades, tanto em termos culturais, quanto em termos econômicos. As oportunidades estariam, assim, mais democratizadas e ao alcance dos indivíduos. As fronteiras virtuais se tornam mais porosas e fáceis de ser transpostas. Por sua vez, o atual momento da sociedade revela que as fronteiras físicas se dirigem em caminho oposto: transitar entre países se torna cada vez mais difícil e mais obstaculizado.

Em se tratando de Brasil, as expressões culturais são facilmente levadas de um lugar para outro, propiciando um intercâmbio entre cidades e estados. As ideias e ideologias também transitam com certa facilidade, muito disso em decorrência da facilitação do acesso à internet. A bem da verdade, há sempre a suspeição de que o domínio da comunicação social não permite uma filtragem midiática democrática, uma vez que a dominação das mídias parece guardar correspondência com o poder das elites políticas e econômicas, e o resultado é que enquanto para estas suas divulgações têm o crivo de verdades, para as mídias alternativas e populares, à míngua de poder político e econômico permite o questionamento de sua consistência

Nessa esteira, divulgou-se promessas, discursos de liberdade individual para o empreendedorismo, de crescimento profissional/financeiro e mesmo pessoal pelo aumento de oportunidades, etc. De maneira muito semelhante, o capitalismo também trouxe promessas, promovendo o discurso de liberdade de empreender, de oportunidades de crescimento profissional/ financeiro e a grande oferta de bens de consumo para a satisfação pessoal. O indivíduo tem a possibilidade de entrar no mercado de trabalho, ascendendo profissionalmente e alcançando novos patamares financeiros, para assim poder adquirir bens de consumo. 
Canclini (2007, p. 29) afirma que a globalização pode ser observada como um conjunto de estratégias direcionadas à consolidação de "conglomerados industriais, corporações financeiras, cinema, televisão e da informática", visando dominar os recursos naturais e culturais dos países mais pobres. Por outro lado, a globalização também permeia o imaginário coletivo e individual, ao vender a ilusão de que "dois e dois, que sempre somaram quatro, podem ser transformados em cinco ou até seis".

Dessa forma, quando se fala em globalização, tanto em termos econômicos quanto em termos culturais, imediatamente se pensa na abertura do mercado, na troca do capital financeiro e econômico entre os países, bem como na troca de valores culturais e sociais. Consideram-se o capitalismo e a globalização como faces de uma mesma moeda, um proporcionando suporte ao outro.

O capitalismo, a modernidade e a globalização trouxeram novas demandas no campo social, jurídico e econômico. Tal questão importa em um novo comportamento de dois atores principais: o indivíduo, inserido no epicentro do novo momento da sociedade, pelo discurso para além do discurso liberalista clássico e o Estado, agente responsável por criar, efetivar e fiscalizar os mecanismos de controle e direção da sociedade, de um modo débil, nunca de um modo forte intervindo nas relações econômico-financeiras e dos direitos sociais.

Adota-se o entendimento de que o indivíduo deve ter liberdade para se posicionar no novo sistema, escolhendo onde e como atuar. Já o Estado não deve exercer seu papel orientador e controlador das regras econômicas, bem como mostrar-se aberto no que tange ao surgimento de novas regulações sociais no seio da sociedade. Portanto, o Estado tem papel fundamental na tarefa de evitar que o indivíduo vire mero objeto.

Tendo em vista este novo momento, o Estado, ao conduzir a sociedade sob seu monopólio e mediante uma atuação jurídica formalista e estritamente positivista, não consegue mais atender aos anseios sociais e não promove, de forma concreta e eficiente, a pacificação dos conflitos que afligem o indivíduo. Neste prisma, tem-se o esgotamento do modelo proposto pela corrente monista, concepção que se consolidou durante a modernidade, que considera o Estado como o único detentor da produção de normas jurídicas ${ }^{4}$. Neste sentido, tem-se que "enquanto sinônimo de direito estatal, o direito encerra-se nos textos legais emanados do Poder Legislativo. Nesse contexto, a lei vale pelo simples fato de ser lei, de modo que sua legitimidade decorre dos procedimentos previamente estabelecidos" (CARVALHO, 2013, p. 14).

Não é possível uma visão ampla e clara de um ordenamento jurídico sem que se compreendam outros fatores advindos da sociedade. Portanto, a norma jurídica não deve ser analisada isoladamente e apenas utilizando aspectos procedimentais. Atento a isso, Wolkmer entende ser vital o contexto social no qual a norma está inserida:

4 O que significa que nas relações sociais para determinado tipo de pluralismo jurídico os indivíduos seriam autores dos seus próprios contratos, transações e o Estado teria o seu feixe legal de normas basilares.

Anota-se, contudo, que o Brasil foi dos últimos países a adotar com mais ênfase o processo ultraliberal, em razão dos governos petistas. Muito embora, desde então já se faziam críticas as negociações promovidas por este partido, que aparentavam a necessidade de coalizão. 
Não se pode captar a plena dimensão de um sistema, de uma sociedade e de uma cultura sem a constatação múltipla de fatores causais inerentes à historicidade humana. Privilegiar, na análise, uma dada instância ou elemento fenômeno (Estado, Direito etc.) como expressões da vida produtiva organizada implica refletir sobre a especificidade da formação social (sociedade corporativo-estamental, organização representativa burguesa etc.), o modo de produção da riqueza (sistema econômico feudal, capitalista etc.), a ideologia como doutrina/crença unificadora e justificadora de mundo (liberalismo, individualismo) e, finalmente, sobre a configuração do modelo de organização político-institucional, ou seja, a instância maior de poder (pluralidade de centros de poder, descentralização administrativa e/ou centralização estatal etc.). (WOLKMER, 2015, p. 23).

O monismo preconiza a ideia de que o ordenamento jurídico é autossuficiente e se legitima no monopólio de regulamentação jurídica, ao passar por um procedimento previamente estabelecido na própria lei. Portanto, a lei se legitima nela própria, e qualquer regulamentação que se estabeleça fora ou concomitantemente a ela não é considerada válida, sendo afastada de pronto. Como efeito do monismo jurídico/monopólio estatal há o descolamento da norma jurídica da realidade social, uma vez que, como se sabe, aquela decorre de uma necessidade constatada no seio da sociedade e, muitas vezes, há um grande período temporal entre o fato social e a regulamentação jurídica. A realidade jurídica é, então, uma "realidade autônoma e altamente abstrata". Neste particular, tem-se o discurso hermenêutico do "legislador racional e neutro", somado à necessidade extrema da segurança jurídica, como legitimadores do caráter justo, universal e autossuficiente do direito, no caso, o direito positivo (CARVALHO, 2013, p. 15).

O ponto de partida do pluralismo jurídico é o esgotamento do modelo jurídico estritamente positivista, bem como a ausência de respostas eficazes aos anseios sociais. Dessa forma, imperioso se faz construir/reconhecer uma nova cultura jurídica, na qual a sociedade tenha efetivamente voz e participe da formação da vontade politica e jurídica do Estado. Wolkmer (2015, p. 14), um dos percussores do tema no Brasil, definiu a expressão pluralismo jurídico como "a multiplicidade de manifestações ou práticas normativas num mesmo espaço geopolítico, interguiadas por conflitos ou consensos, podendo ser ou não oficiais e tendo sua razão de ser nas necessidades existenciais, materiais e culturais".

O pluralismo de Wolkmer no entender desse artigo, busca ressignificar o pluralismo na vertente da América Latina, aonde se sabe que há uma diferenciação do pluralismo escandinavo e mesmo do pluralismo europeu. Então mesmo que distante, talvez seja perspicaz prenotar que o pluralismo como o positivismo não se institui em unicidade, mas há sentidos que lhe dão plurivocidade.

O pluralismo jurídico trabalha ativamente a construção de uma nova cultura jurídica voltada para o reconhecimento de práticas que surgem no seio social. Dessa forma, contrapõese frontalmente ao monismo jurídico, mas não por negar o Direito Estatal, e sim por referendar outras formas de manifestações jurídicas que não somente as oriundas das produções legislativas “oficiais". Esta é a vertente trabalhada na proposta de Antônio Carlos Wolkmer: um pluralismo jurídico fundado numa cultura comunitária participativa. Dessa forma, há a ressignificação 
dos papéis sociais, anulando a barreira existente entre as classes sociais, redemocratizando os institutos e reposicionando o cidadão no ideário de justiça (MOLL, 1994, p. 92).

Quando se pensa em uma nova cultura jurídica, há que se ter em mente a necessidade de se reposicionar os institutos, valorizando mais a participação popular na formação da vontade política e jurídica do Estado. Para que isso ocorra de forma efetiva, devem-se retirar as barreiras existentes entre as classes sociais, trazendo aqueles que pouco ou nada participam para uma posição mais protagonista em termos sociais, políticos e jurídicos.

David Rúbio (2014, p. 26-27) sintetiza bem o entrave que é separar o mundo jurídico do contexto sociocultural:

\footnotetext{
Da maneira como o interpretamos a partir do paradigma da simplicidade, temos a tendência de separar e segmentar as diversas partes que compõem o mundo jurídico e dividir sua complexa e plural realidade. Com isto provocamos uma ausência de comunicação entre seus distintos elementos. (...) Reduz-se o Direito ao direito estatal, ignorando outras expressões jurídicas não estatais (pluralismo jurídico) (...) O resultado é a absolutização da lei e do Estado, bem como a burocratização de sua estrutura; também se reduz o saber jurídico à pura lógica analista e normativa, ignorando as conexões entre o jurídico, o ético e o político, não apenas do ponto de vista externo do direito, mas também internamente. (...) Nesta dinâmica há um esvaziamento e isolamento do humano em sua dimensão corporal, indivíduos com nomes e sobrenomes com necessidades e sujeitos que produzem realidade.
}

Ao se direcionar o olhar apenas num único sentido, o da lei estritamente positivista, fundada apenas num procedimento previamente estabelecido, há o risco de se ignorar os múltiplos fatores sociais e políticos oriundos de uma sociedade que se mostra cada dia mais complexa e cheia de desafios. São questões fundamentais no atual momento, especialmente quando se parte do pressuposto de que o capitalismo sofre de esgotamento. Cai o véu das promessas não cumpridas e revela-se o grande paradoxo do capitalismo: o abismo de desigualdade existente entre os ricos (países, empresas e indivíduos) e pobres aumentou, a globalização não favoreceu economicamente todos que dela participaram e o "bolo não foi devidamente repartido".

Tanto o esgotamento do capitalismo quanto o deficit de atuação estatal atingem a todos, porém são aqueles que estão em contextos periféricos que mais sentem este processo. Os países pobres cedem cada vez mais parcelas de sua soberania e entram em acordos comerciais que não alteram seu status quo comercial; seus índices de desenvolvimento humano permanecem baixos e estacionados. No campo empresarial, as companhias transnacionais dominam o mercado mundial, revelando também que a globalização econômica não proporcionou a entrada de novos atores; mantém-se o capital nas mãos de poucas e restritas empresas. Por sua vez, os indivíduos também não se posicionam em um patamar privilegiado; pelo contrário, a desigualdade no mundo não diminuiu, e o poder financeiro, econômico, e consequentemente jurídico, concentrase em poucas e privilegiadas mãos.

E de que há igualmente um único pluralismo é não compreender que os direitos estatais e emanados pela sociedade são passíveis de sofrerem transformações na direção de avanço ou 
de retrocesso, sendo necessário de que aqueles que detenham o poder político se aproximem de ambos. Nesse diapasão, a Constituição de 1988 é um grande suporte à compreensão do constitucionalismo brasileiro. Assim se afirma porque esta pode funcionar como uma trava à tirania do poder estatal, desde que os seus fundamentos sejam adotados com intenções verdadeiras, o que se reconhece como uma tarefa hermenêutica que pode trazer situações de dificuldades palpáveis.

No entanto, o povo livre das opiniões irracionais que podem ser propostas pela tirania do populismo que se enquadra no anárquico capitalismo tão comum nos dias atuais de vários Estados latino-americanos. Esta nova fundamentação parte necessariamente do aprofundamento da democracia participativa, do resgate dos atores que compõem o cenário social e jurídico, bem como da aproximação entre o Direito e a realidade. Não pode essa realidade ser distorcida a ponto de que o que seja considerado como Povo seja uma massa manipulada pelos altos setores que consigam com seus poderes adulterar a realidade social.

\section{O PLURALISMO JURÍDICO NA AMÉRICA LATINA}

A Europa influenciou significativamente diversos campos da América Latina. Sociedade, cultura, economia e o pensamento teórico e jurídico são exemplos de setores que receberam carga do pensamento europeu. Quando se importa (ou se recebe forçadamente) um modo de vida fechado de outro lugar, sem se considerar a realidade regional, há sério risco de se ignorar importantes peculiaridades, determinantes para a vida daquele lugar.

A colonização europeia na América Latina revelou-se um processo em que os reais benefícios ficaram para o colonizador, restando ao colonizado os laços de dominação e subserviência. Sabe-se que lugar algum que objetive a construção de um sistema (em qualquer área) sólido e significativo pode ignorar a própria história. Dessa forma, sem querer afastar peremptoriamente a influência europeia, é necessário descolar-se dos laços da colonização e assim fortalecer a identidade da América Latina, sem negar, entretanto, os efeitos provocados pela globalização.

Quijano (2005, p. 227) defende que a globalização é a culminação de um processo que se iniciou com a constituição da América Latina e do capitalismo/moderno e eurocentrado, o que determinou um novo padrão de poder global. A classificação social da população de acordo com sua raça originou relações de dominação e império de umas em relação às outras. Dois processos teriam sido fundamentais para a constituição de um novo padrão de poder: a) a codificação das diferenças entre conquistadores e conquistados, através da raça, com a superioridade de uma sobre a outra; b) a articulação de todas as formas de controle e produção do trabalho em torno do capital e do mercado mundial.

Impossível se pensar em América Latina sem entender o processo de construção da ideia de raça e como isso foi fundamental para a divisão de classes e trabalho como ocorre atualmente. 
Neste sentido, disserta Quijano:

\begin{abstract}
A ideia de raça, em seu sentido moderno, não tem história conhecida antes da América. Talvez se tenha originado como referência às diferenças fenotípicas entre conquistadores e conquistados, mas o que importa é que desde muito cedo foi construída como referência a supostas estruturas biológicas diferenciais entre esses grupos. (...) Em outras palavras, raça e identidade racial foram estabelecidas como instrumentos de classificação social básica da população. (...) Essa distribuição racista de novas identidades sociais foi combinada com uma distribuição racista do trabalho e das formas de exploração do capitalismo colonial. Isso se expressou, sobretudo, numa quase exclusiva associação da branquitude social com o salário e logicamente com os postos de mando da administração colonial. Assim, cada forma de controle do trabalho podia ser ao mesmo tempo um controle de um grupo específico de uma forma específica de trabalho e um controle de um grupo específico de gente dominada.
\end{abstract}

A construção da ideia de raça e divisão organizacional do trabalho, trazida por Quijano, trabalha silenciosamente na justificativa na manutenção do status quo social. Se inicialmente negros e mestiços eram ligados aos colonizados e os caucasianos aos colonizadores, hoje persiste uma distribuição semelhante.

No caso brasileiro, a população mais pobre ainda é predominantemente composta por negros, conforme estudo feito pelo Instituto de Pesquisa Econômica Aplicada - IPEA. Enquanto a média salarial de um homem branco é de $\mathrm{R} \$ 1.491,00$ (mil quatrocentos e noventa e um reais), o homem negro recebe em média $\mathrm{R} \$ 833,50$ (oitocentos e trinta e três reais e cinquenta centavos). A situação da mulher negra é ainda pior: recebe o valor de $\mathrm{R} \$ 544,40$ (quinhentos e quarenta e quatro reais e quarenta centavos), enquanto para a mulher branca o valor é de R\$957,00 (novecentos e cinquenta e sete reais) ${ }^{5}$. O valor salarial é reflexo da organização do mercado de trabalho e acha-se intimamente ligado à questão de raças. Nos termos da doutrina de Quijano, a construção realizada pelos colonizadores se consolidou na prática.

Quanto à América Latina, sabe-se que o continente é repleto de países que passaram por momentos de autoritarismo e mergulho em períodos sem liberdade social, política e até mesmo jurídica. Significativa parcela dos países é ainda hoje marcada por profunda desigualdade social, e seus regimes, apesar de formalmente democráticos, ainda estão em fase de consolidação política e democrática. O grande desafio latino-americano é romper verdadeiramente com a cultura autoritária, consolidando os regimes democráticos e o pleno respeito aos direitos fundamentais dos indivíduos.

Nesse contexto, o pluralismo jurídico constitui uma importante alternativa para suprir a lacuna e preencher importantes espaços onde o Estado não chega e/ou não oferta repostas suficientes e satisfatórias. A realidade apresentada pela América Latina propiciou o pensamento de alternativas para superar a colonização e uma das alternativas encontra-se no seio da própria comunidade e não em modelos transplantados de outros países.

O pluralismo jurídico indígena é fortemente encontrado na Bolívia, Peru, Equador, tendo, inclusive, reconhecido nas Constituições a jurisdição indígena. Raquel Fajardo, tal fato propiciou

5 Dados retirados do site http://www.ipea.gov.br/retrato/pdf/revista.pdf. Acessado em 16 de fevereiro de 2020. 
o reconhecimento pelo Estado do direito costumeiro e das funções jurisdicionais dos povos indígenas (2015, p. 35).

O reconhecimento do pluralismo jurídico passou por três ciclos constitucionais, com uma evolução progressiva do tema. Houve o ciclo do constitucionalismo multiculturalista (19821988), o ciclo do constitucionalismo pluricultural (1989-2005), e o ciclo do constitucionalismo plurinacional (2006-2009).

O ciclo 1 trouxe a concepção de multiculturalismo, multilíngue da sociedade e diversidade cultural. Alguns países reconheceram formalmente em suas Constituições o multiculturalismo6 (FAJARDO, 2015, p. 10).

O ciclo 2 é pontuado pelas afirmações nas Constituições de direitos individuais e coletivos, da identidade e diversidade cultural, com conceitos de "nação multiétnica/multicultural" e de "Estado Pluricultural" (FAJARDO, 2015, p. 10-11).

Finalmente, ciclo 3 é tratado como constante em processos constituintes de dois países - Bolívia e Equador, e possui ligação com a aprovação da Declaração de Nações Unidas dos direitos dos povos indígenas. (FAJARDO, 2015, p. 46).

As Constituições pós ditatoriais trazem e modo explícito um projeto descolonizador, rompendo com as raízes da colonização para dar espaço a um modelo próprio e mais adequado à realidade cultural, social, política e jurídica latino-americana. O pluralismo jurídico encontra então espaço fértil para crescer e irradiar efeitos a toda a sociedade, aproximando o Direito da realidade, o que o monismo tem grandes dificuldades para viabilizar.

A utilização de expressões como reconhecimento e proteção da diversidade étnica e cultural (Colômbia), direito à identidade étnica, proteção da pluralidade (Peru), soberania multiétnica (Bolívia), respeito à interculturalidade (Venezuela), é relevante para deixar claro o deslocamento do Estado para suas raízes históricas, descolando-se do colonizador (Quadro 1). Por sua vez, o reconhecimento do pluralismo jurídico e da jurisdição indígena (Direito consuetudinário e inconstitucionalidade indígena) também consta de forma expressa nas Constituições de Colômbia, Peru, Bolívia, Equador e Venezuela (Quadro 1.1), estabelecendo a forma como os povos indígenas e as comunidades campesinas nativas (caso do Peru) exercem sua jurisdição, estabelecendo um importante ponto do pluralismo jurídico, a saber, a coexistência com a jurisdição estatal.

No terceiro ciclo do desenvolvimento do pluralismo jurídico, Equador e Bolívia aparecem como referências. Algumas passagens importantes merecem destaque, especialmente por seu caráter emancipatório e pelo descolamento dos Estados boliviano e equatoriano de seu status de colonizados. Resgata-se, portanto, a fase pré-colonial, em que estes Estados deixam de ser objeto para se tornar sujeitos de seus próprios atos, escolhas e políticas.

$\mathrm{O}$ art. 26 da Constituição boliviana reconhece expressamente o colonialismo e um momento anterior a ele, porquanto menciona os povos indígenas originários e seu domínio sobre seus territórios. Já a Constituição equatoriana de 2008, em seu art. 1716, estabelece que o Estado garantirá o respeito às decisões indígenas pelas instituições e autoridades públicas, e que estas estarão sujeitas ao controle de constitucionalidade. 
Sobre o constitucionalismo equatoriano e boliviano, observa Bartolomé Clavero (2015, p. 116-117):

\begin{abstract}
O caráter plurinacional (da Bolívia como Estado) está relacionado com o eixo descolonizador como rota desconstrutora do Estado republicano, colonial e liberal. O plurinacional guarda relação com o reconhecimento da preexistência colonial das nações indígenas originárias e pôde ser escrito na conjuntura reconstituinte da Bolívia. (...) A Constituição do Equador somente se pronuncia contra o colonialismo no preâmbulo e no capítulo das relações internacionais, sem relacioná-lo com os povos indígenas interiores, mas o tratamento que dá aos direitos destes povos coincide substancialmente com o que lhes proporciona a Bolívia sob o imperativo da descolonização interna. (...) O Equador e a Bolívia ultrapassam, assim, de longe e com folga, a incorporação constitucional de direitos humanos usual na América Latina, uma vez que os precedentes limitam-se aos direitos contidos em convenções, pactos ou tratados.
\end{abstract}

Dessa forma, o pluralismo jurídico latino-americano visa romper com amarras coloniais, ressignificando o papel do Estado e do ordenamento jurídico. Aproxima-se, portanto, o Direito da sociedade, facilitando o entendimento de peculiaridades que, muitas vezes, fogem ao controle e ao entendimento do Estado. O reconhecimento do Direito e da jurisdição indígena evidencia um afastamento dos "colonizados" dos seus "colonizadores", atentando para peculiaridades culturais próprias da América Latina.

\title{
5 A EXPERIÊNCIA BRASILEIRA: TEORIAS E CONTRIBUIÇÕES
}

A sociedade moderna é repleta de desafios e contradições, como visto em pontos anteriores deste trabalho. Quando se analisam países periféricos, onde há um grande déficit de efetivação de direitos básicos, a situação se agrava consideravelmente. Mesmo em países onde as Constituições preveem um bom catálogo de direitos fundamentais, como no caso do Brasil, há problemas no campo da observância desses direitos. Sem a efetivação, o Direito acaba por se tornar letra morta.

Tal fato fortalece a necessidade de sair do campo formal de direitos para o campo material, com medidas efetivas que proporcionem ao indivíduo o acesso efetivo aos direitos fundamentais, especialmente aqueles ligados ao princípio da dignidade da pessoa humana. O Brasil não foge à regra da complexidade, apresentando particularidades sociais, culturais e jurídicas. O País também apresenta profundos problemas, com grande desigualdade social, significativa parcela da população em situação de pobreza, elevados índices de analfabetismo etc. Tais problemas são agravados pela falta de prestação de serviços básicos de saúde e educação, o que atinge sobremaneira as pessoas que vivem em contexto periférico.

Posto o panorama brasileiro e superada a ideia de que o pluralismo jurídico é a negação do Direito proveniente de fontes estatais, passa-se à análise das contribuições da teoria no Brasil, traçando-se um breve histórico e mencionando suas principais nuances e autores.

A herança portuguesa deixou raízes e influenciou o Direito brasileiro, especialmente no que tange à estrutura burocrática que aqui se instalou. Os índios que aqui viviam tiveram tradições e 
costumes misturados com o "modo de vida" do homem branco português, mais uma expressão da influência do colonizador sobre os colonizados. A burocracia e a tradição jurídica advinda de Portugal, estritamente ligada à cultura patrimonialista estatal, instalaram no Brasil um Estado excessivamente formalista, sem que ocorresse a construção da ideia de cidadania. O Estado brasileiro não nasceu através de uma reivindicação popular, e sim baseado exclusivamente na figura do monarca (MALISKA, 2009, p. 25).

O feudalismo brasileiro guarda, segundo Faoro (2001, p. 153), certa similitude ao operacionalizado no continente europeu; "a expressão plástica da tese do feudalismo brasileiro mostra, com abundância de provas, o processo que a ditou. O senhor de latifúndios, e de escravos - o senhor de engenho -, se incorpora a uma categoria social, a aristocracia ou a nobreza de ordem rural".

O aparelho burocrático estatal não se alterou significativamente com o fim da monarquia e a passagem para a República. Mesmo com diversas reformas ${ }^{6}$ implementadas (ou tentadas), o Estado brasileiro ainda é formalista, burocrático e afastado do povo (principal destinatário de suas ações).

O Direito também não percorreu caminho muito diferente, não se aproximando realmente do indivíduo. Atualmente, ainda se verifica um afastamento do Direito da sociedade, especialmente no tocante à faixa da população hipossuficiente financeiramente. Aqui, encaixase a questão do esgotamento do modelo estritamente positivista, preconizado pelo monismo jurídico. Em razão do deficit estatal e da existência de lugares "onde o Estado não chega", o Brasil se mostra como um fértil celeiro para o pluralismo jurídico. Esse imaginado "celeiro" tem sido feito por teorias críticas do Direito. Essas teorias possui uma legitimidade conquanto se pauta na multidisciplinaridade possível de leituras da realidade social.

De acordo com Wolkmer (2015, p. 85):

\begin{abstract}
Parece claro, por conseguinte, que os sintomas das contradições dos países periféricos latino-americanos devem ser buscados na conjugação dos fatores internos e externos, pois a dependência é produto tanto das condições criadas pelo sistema-mundo de dominação político-econômico mundial quanto das relações de classes e da ação ético-cultural dos agentes e dos grupos na esfera de colonização de cada nação e de cada Estado. Nesse rumo de indagação pautada pela dialética de um processo global (somatório dos condicionantes exógenos e endógenos), torna-se essencial, para compreender o "periférico" e a "dependência" numa sociedade como a brasileira, ter muito claro o papel interno de colonização nas relações sociais e nas contradições de classes.
\end{abstract}

Assim, o Brasil, assim como os demais países da América Latina, tem fortes traços da colonização, além da peculiaridade das contradições de classes aqui existentes. Outra questão

6 O DASP (Departamento de Administração do Serviço Público), criado durante o governo Vargas, em 1933, objetivou a implantação de uma burocracia weberiana no país, ou seja, um aparelho burocrático moderno e racional, deslocando-se da burocracia patrimonialista. Também se tentou reformar o aparelho estatal durante o período autoritário, em 1967, através do Decreto-Lei n 200, visando contornar a rigidez das estruturas da administração direta, introduzindo assim um espírito gerencial privado, oriundo do setor paraestatal (PINHO, 1998). 
particular brasileira é o papel do Poder Judiciário e sua cultura de burocracia, ineficiência material, demora processual e, principalmente, as barreiras que afastam os indivíduos hipossuficientes do acesso à Justiça. É necessário diferenciar o papel ideal do Poder Judiciário, como agente transformador, e o que ele de fato representa: agente de manutenção do status quo, estritamente ligado a uma lógica econômica - o "custo" do Direito acima do Direito propriamente dito, conforme apontado no início deste trabalho.

A verdade, infelizmente, é que a cultura jurídica brasileira é liberal e positivista; conforme se verifica na história brasileira, não é o Poder Judiciário marcado por uma postura "independente, criativa e avançada em relação aos graves problemas de ordem política e social. Pelo contrário, trata-se de um órgão elitista, distanciado da sociedade" (WOLKMER, 2015, p. 107).

O pluralismo jurídico brasileiro passou por momentos diversos, tanto na época colonial feudal, em movimentos ligados aos direitos indígenas, como também durante o período autoritário que o País vivenciou. Todavia, é na questão da diferença acentuada entre as classes sociais e na efetivação de direitos fundamentais para as classes hipossuficientes que o pluralismo jurídico brasileiro encontra campo fértil para atuar.

No que tange ao pluralismo indígena, o Brasil trouxe algumas previsões na Constituição da República Federativa de 1988 - CRFB/88, mas nada perto do previsto nas Constituições de outros países latino-americanos. $\mathrm{O}$ art. 231 da $\mathrm{CRFB} / 88$ reconheceu aos índios sua organização social, costumes, línguas, crenças e tradições, bem como o direito originário sobre suas terras. Mas será que este artigo, ao citar a organização social, também incluiu a jurídica?

Rodrigo dos Santos (2013, p. 278) advoga que "dentro das noções de organização social, costumes, crenças e tradições, inclui-se inegavelmente a questão da organização jurídica (em seus sentidos administrativos, legislativo e judiciário)". Dessa forma, entende o referido autor que o problema está em o intérprete encontrar uma forma de conciliar essa organização jurídica indígena com a oficial, proveniente de meios estatais.

Em relação a isso, propõe uma maior ousadia do intérprete constitucional, não devendo a Constituição ser vista de modo convencional ou tradicional. É necessário romper com o formalismo que sempre acompanhou o Poder Judiciário. Continua o autor (2013, p. 278): “deve o intérprete constitucional reconhecer, concretizando 'a vontade constitucional', que a partir de 5 de outubro de 1988 os povos indígenas brasileiros gozam de verdadeira soberania (e não somente autonomia)".

A proposta apresentada por ele é interessante, mas em razão do objeto deste artigo não será exaustivamente analisada. $O$ certo é que, aparentemente, o constituinte brasileiro não teve a mesma intenção que os dos demais países latino-americanos, que trouxeram diversos dispositivos abordando e disciplinando o tema.

Uma importante vertente é a construída por Antônio Carlos Wolkmer ${ }^{7}$, chamada de pluralismo jurídico comunitário-participativo, fruto de análise do contexto pelo qual passou o país no período de redemocratização. Este autor acentua a importância dos movimentos sociais

7 A construção de Wolkmer foi fruto de tese de doutorado apresentada na Universidade Federal de Santa Catarina na década de 90 . 
neste processo, como fonte de produção jurídica; destaca que o "fato de que a insuficiência de fontes clássicas do monismo estatal determina o alargamento dos centros geradores de produção jurídica, mediante outros meios normativos não convencionais, privilegia as práticas legais engendradas por novos sujeitos sociais" (2015, p. 162). O pluralismo jurídico comunitárioparticipativo introduz a importância da participação efetiva de novos sujeitos sociais, oriundos do centro da sociedade.

Neste sentido, ressalta Wolkmer (2015, p. 166 e ss.):

\begin{abstract}
Trata-se de nova forma de gerar legitimidade a partir de práticas e relações sociais surgidas na concretude plural e efetiva do cotidiano. O centro de gravitação e de produção jurídicos aparece através de "pactos setoriais", "negociações coletivas", "arranjos sociopolíticos" e "convenções normativas", firmadas por identidades coletivas e por associações voluntárias, que passam a ser encaradas como fontes do Direito num certo sentido prevalecente e não subordinado ao formalismo das fontes formais. (...) As novas exigências, necessidades e conflitos em espaços sociais e políticos fragmentados, tensos e desiguais, envolvendo classes, grupos comunitários e coletividades plurinacionais, importam na utilização de novos procedimentos, novas formas de ação compartilhada e de diálogo intercultural (prático-teórico). É nesse interregno que aparecem novas identidades coletivas capazes de introjetar direitos que não passam nem pela positivação estatal nem pelas instituições representativas convencionais. Trata-se do pluralismo de formulações jurídicas provenientes de produção normativa, adquirindo um caráter múltiplo, informal e mutável. A validade e a eficiência dessas práticas de Direito e Justiça Comunitários, que não se sujeitam ao formalismo a-histórico das fontes tradicionais (lei escrita e jurisprudência dos tribunais), estão embasadas nos critérios de uma nova "legitimidade", gerada a partir de valores, objetivos e interesses do todo comunitário, e incorporados através da mobilização, da participação e da ação compartilhada. (grifo nosso)
\end{abstract}

Dessa forma, o pluralismo jurídico proposto por Wolkmer é fundado na participação popular, destacando-se a importância dos movimentos sociais como participantes ativos da produção jurídica, especialmente fundada sobre os valores, objetivos e interesses comunitários. Importante mencionar que este pluralismo jurídico se amolda aos anseios da sociedade e contempla parcelas da população que, muitas vezes, têm dificuldades em algum campo: social, econômico, político e de previsão e efetivação de direitos. Nele incluem-se as minorias: pobres, mulheres, índios, trabalhadores, negros. O pluralismo jurídico comunitário-participativo é um instrumento que tanto proporciona voz para a sociedade, quanto pode operar para a efetivação de direitos fundamentais no Brasil.

O sociólogo português Boaventura de Sousa Santos, em tese de doutorado apresentada na Universidade de Yale no ano de 1973, analisou a formação e a implementação do discurso jurídico dentro de uma comunidade periférica (Jacarezinho) na cidade do Rio de Janeiro, a que ele denominou Pasárgada. O autor comparou o "direito oficial" dos Estados contemporâneos, especialmente os capitalistas, com o encontrado em Pasárgada, acentuando que a produção jurídica é, retoricamente, mais ampla que o direito estatal (2014, p. 31). Nesse sentido, apontou que “o espaço jurídico retórico do discurso jurídico é suscetível de variação; o direito de Pasárgada tende a apresentar um espaço retórico mais amplo que o do direito estatal” (2014, p. 34). 
O Estado não se faz presente o suficiente para regular a contento as situações sociais experimentadas numa comunidade periférica. Há várias faces deste deficit, conforme já abordado neste trabalho, ressaltando especialmente a questão dos direitos fundamentais violados. Mas a questão vai além, pois há relações cotidianas dos indivíduos que residem em periferias, sem previsão de ordem legislativa ou sem cobertura pelo Poder Judiciário. Neste contexto de ineficiência estatal do direito estritamente positivado é que floresce o pluralismo jurídico no seio das periferias, possibilitando o nascimento de produções jurídicas "não oficiais".

Mesmo constatando isso, o autor entende que há um problema no grau de institucionalização do direito de Pasárgada, considerando-o baixo. Acentua que a função jurídica é exercida, em grande parte, pelas associações dos moradores, acrescendo a estas a presença de líderes individuais e de organizações religiosas. Não há uma divisão muito clara das funções dos líderes de associações na prevenção de litígios (ratificação de negócios jurídicos), o que reforça a deficiência da institucionalização por ele apontada (2014, p. 38-39).

Além disso, a burocracia, a formalidade e a cerimonialidade encontradas no Poder Judiciário não existem em Pasárgada, prevalecendo, na resolução de conflitos nas periferias, a informalidade de procedimento e de tratamento, especialmente a mediação. Tal fato é decisivo e aproxima o indivíduo do direito de Pasárgada, afastando-o do direito estatal. Boaventura constatou que a questão das moradias é muito forte e gera muitos conflitos entre os moradores das periferias, especialmente no que tange à possível ilegalidade, aos olhos do direito oficial, das habitações.

Anota Boaventura (1988, p. 14):

O direito de Pasárgada é um direito paralelo não oficial, cobrindo uma interação jurídica muito intensa à margem do sistema jurídico estatal (o direito do asfalto, como lhe chamam os moradores das favelas, por ser o direito que vigora apenas nas zonas urbanizadas e, portanto, com pavimentos asfaltados). Obviamente, o direito de Pasárgada é apenas válido no seio da comunidade e a sua estrutura normativa assenta na inversa da norma básica (grundnorm) da propriedade, através da qual o estatuto jurídico da terra de Pasárgada é consequentemente invertido: a ocupação ilegal (segundo o direito do asfalto) transforma-se em posse e propriedade legais (segundo o direito de Pasárgada).

O pluralismo jurídico de Boaventura foi muito festejado na época e obteve ampla repercussão, mas também foi alvo de severas críticas. Lucas Borges de Carvalho (2013, p. 1820) observa que um grupo de críticos apontou certa impropriedade na aplicação do conceito de pluralismo jurídico à realidade brasileira e latino-americana. Também se criticou a "falta de originalidade cultural" do direito de Pasárgada, indicando que, ao contrário dos fenômenos clássicos do pluralismo jurídico, a comunidade se insere no contexto capitalista e estaria, portanto, imbuída dos mesmos valores.

Ora, não seriam as favelas resultantes de uma falha do sistema capitalista e frutos da má distribuição de renda e da ausência de prestação de serviços estatais? Dessa forma, esta crítica 
ao pluralismo jurídico de Pasárgada não procede, especialmente por serem os indivíduos que ali residem, em muitas situações, vítimas do próprio sistema.

Já Marcelo Neves criticou o "romantismo" do pluralismo jurídico proposto por Boaventura ao observar Pasárgada e a necessidade de se garantir autonomia e eficácia ao próprio direito estatal. Também observou o autor que a teoria era utópica e não adequada à realidade latinoamericana. Segundo ele, há uma miscelânea social, o que implica a dificuldade de se construir uma identidade da esfera da juridicidade (1991).

Interessante é o caráter utópico atribuído ao pluralismo jurídico por alguns autores, quando a utopia está no perfeito funcionamento das esferas jurídicas provenientes unicamente de fontes estatais. O deficit estatal é grande e, conforme afirmado neste trabalho, atinge especialmente indivíduos em contexto periférico. O ideal seria que o Estado pudesse proporcionar a todos, sem distinção, acesso a serviços públicos, inclusive à Justiça (prevenção e resolução de conflitos), mas isso, infelizmente, ainda se acha no campo da utopia.

Ademais, cumpre ressaltar que Boaventura reformula sua teoria de pluralismo jurídico, conforme adverte Wolkmer (2015, p. 222-223), substituindo o termo por "pluralidade jurídica" e aprofundando o estudo de sistemas globalizados e ordenamentos jurídicos transnacionais, construindo uma ideia pós-moderna de Direito. Dessa forma, há que se analisar Pasárgada em seu próprio tempo, especialmente levando em consideração que a sociedade se encontra em constante movimento e alteração. O pluralismo jurídico explanado por Boaventura, fruto de sua tese de doutorado, foi importante para que daí surgissem novas vertentes, adequadas a cada espaço e tempo.

No livro intitulado O Direito dos Oprimidos - Sociologia crítica do Direito 1, Boaventura traz novas concepções e observações sobre o tema; afirma que "a transformação ao longo destas décadas foi muito mais que teórica e política; foi uma transformação epistemológica". Dessa forma, com o passar dos anos, o sociólogo, ao observar a movimentação da sociedade, entendeu necessária uma reformulação e adequação da própria teoria pluralista, mais condizente com as novas demandas sociais, políticas e jurídicas. Todo trabalho necessita ao ser publicado em outras circunstâncias de ser revisitado. Ainda que não tenha a profundidade do artigo original.

Ademais, cumpre-nos contextualizar o pluralismo jurídico com o panorama atual de proliferação do Covid-19, especialmente no que concerne ao impacto que a pandemia pode trazer para indígenas e minorias étnicas e sociais.

Neste item, observa-se a questão da dignidade humana e do direito à vida colhendo -se a necessidade de que o direito à saúde traga implicações na ajuda matéria do Estado e dos grupos econômicos com maior poderia econômico. Esses direitos, ao nosso sentir tem sido fruto dos movimentos sociais em prol da recusa as medidas espoliativas do trabalhador que, a despeito da pandemia lhe é imposto o trabalho e todos os riscos à sua sobrevivência decorrente de sua exposição à pandemia.

Seguidamente, o direito à renda básica mínima à sobrevivência não se confunde com o salário mínimo, que é uma garantia constitucional do trabalhador. Trata-se de uma solidariedade 
que se manifesta pelo Estado estabelecer uma renda mínima para o trabalhador desempregado. Ademais, a realidade tem mostrado que as populações com menor poder aquisitivo são àquelas com maiores dificuldades para permanecerem em casa, seja em virtude de suas profissões não serem mais facilmente exercíveis em teletrabalho ou por não serem trabalhadores formais, necessitando estarem na rua para manutenção da própria subsistência e de sua família.

Soma-se a isso, a dificuldade que estas pessoas estão apresentando para ter acesso ao auxílio anunciado pelo Governo Federal. Tanto o aplicativo da Caixa Econômica Federal que constantemente não funciona adequadamente, quanto as longas filas frente ao referido Banco e também, em muitos casos, na Receita Federal para regularização de dados pessoais. O risco da aglomeração é uma constante e os anúncios do impacto financeiro que tais medidas trarão também.

Há medidas que vem sendo discutidas em campos da sociedade como alternativa para fazer frente ao montante gasto pelo Governo Federal para combater o Covid-19 - tanto no front da saúde em si, como nos auxílios pagos para manutenção de pessoas e empresas. Uma delas é a taxação de grandes fortunas no período da pandemia ou até mesmo posteriormente a ela, possível no âmbito do direito da solidariedade. Bem como a taxação de lucros e dividendos, que curiosamente, mas não surpreendentemente, não ocorre no país.

Por outra parte, ainda que de forma leve, a importância do Estado no âmbito dos direitos sociais e suas eficiências - princípio da eficiência e moralidade administrativa -, evidenciam que os países, mesmo os liberais como a Coreia do Sul e outros asiáticos que mantiveram são os que têm demonstrado capazes de diminuírem as vicissitudes desta e de outras pandemias.

Aqui também tem-se que o pluralismo jurídico e resgate do debate em torno da participação da comunidade na tomada de decisões, bem como a real consideração de populações que estão no cerne da pandemia ocorram.

\section{CONCLUSÃO}

Ao se analisar o caminho pelo qual passou a sociedade, no que tange à regulação social e jurídica, retornando à época feudal e pré-capitalista, identificaram-se fortes passagens de uma forma de pluralismo político e jurídico. Isso muito em razão da grande área rural e do diminuto espaço territorial de cidades, fazendo com que os senhores feudais funcionassem como instância de produção e aplicação da normatização social e jurídica.

Quando se passa para o período mercantilista e capitalista, constata-se o surgimento de novas demandas, especialmente no tocante à regulação das relações de trabalhos e aos anseios ligados às garantias de direitos básicos. A complexidade da sociedade, impulsionada por novas questões trazidas pela modernidade, pelo capitalismo e pela globalização, impõe ao indivíduo uma nova postura diante dos desafios que surgem constantemente.

Duas questões se apresentam em razão do esgotamento do modelo estritamente positivista estatal. De um lado, no que diz respeito ao Poder Legislativo e à produção de leis, tem-se 
que estas, muitas vezes, não alcançam as situações sociais/jurídicas originárias de significativa parcela da população, especialmente os que se encontram em contexto periférico. Por outro lado, o Poder Judiciário ainda tem em suas raízes a influência da burocracia e do formalismo português.

Ademais, o principal destinatário - o povo - pouco participa das ações estatais para a formação da vontade política e jurídica do Estado. O monopólio da produção normativa jurídica não contribui para a alteração deste cenário, pelo contrário, só aprofunda os problemas e o deficit de atuação estatal.

Neste cenário de desafios, o pluralismo jurídico se posta como uma corrente teórica que reconhece em outras fontes, para além do direito estatal, a produção de normas jurídicas, aproximando o Direito da realidade social.

Como apresentado neste trabalho, o pluralismo jurídico latino-americano é rico e já se encontra consolidado nas Constituições de países como Bolívia, Peru e Equador, por exemplo. Tais países reconheceram a existência de uma fonte de produção normativa e instância jurídica não somente proveniente do Estado: a jurisdição indígena. Apesar da pecha de colonizados ainda ser muito forte na América Latina, há que se reconhecer que existia uma nação anterior à chegada dos colonizadores europeus e que muito foi retirado da população nativa daquela época. Portanto, o reconhecimento do direito indígena e das populações originárias campesinas proporciona o que hoje se chama de decolonização ou descolonização, reconhecendo-se as peculiaridades latinas e descolando-se, gradativamente, do modo de vida, do direito e da cultura europeia.

Em se tratando de Brasil, foi visto que também existem questões próprias, estritamente ligadas à questão social e econômica do País. As comunidades periféricas que aqui existem possuem modos e questões próprias, que fogem ao controle e à cobertura do Estado, tanto social quando juridicamente. Fato registrado por Boaventura há muitos anos, mas que, apesar de demandas novas e das alterações ocasionadas pelo passar dos anos, ainda permanecem iguais no quesito ausência de Estado na vida dos indivíduos que se acham em contexto periférico.

Também se ressalta a importante contribuição de Antônio Carlos Wolkmer e de seu pluralismo jurídico comunitário-participativo, que encontra em movimentos populares/sociais uma alternativa para a crise do esgotamento do modelo estritamente positivista. Dessa forma, mais uma vez o pluralismo jurídico cumpre um importante e vital papel na aproximação do Direito à realidade e na busca pela efetivação de direitos, especialmente daqueles indivíduos ditos hipossuficientes.

Por fim, cumpre mencionar que as críticas à "utopia" pluralista não merecem prosperar por duas razões. A primeira é o fato de que o pluralismo não objetiva a extinção ou a substituição do direito oficial, proveniente de fontes estatais - isso é, em verdade, uma má interpretação do pluralismo jurídico. A segunda é que há problemas nas teorias que enxergam apenas o Estado como pacificador das questões sociais e jurídicas da sociedade, cada vez mais complexa e cheia de desafios. Utópico é achar que o Estado é capaz de pacificar todos os conflitos e oferecer respostas satisfatórias e completas às demandas dos indivíduos. 
O momento atual é muito desafiador e precisa ser pensado considerando a sociedade de maneira ampla e inclusiva, não afastando direitos fundamentais ligados à dignidade da pessoa humana, como tem sido visto. Direitos como saúde e educação tem sido frequentemente colocados em xeque e o que tem se mostrado é que sistemas de saúde mercantilizados, como o americano, estão levando pessoas a não procurarem atendimento médico, aumentando o número de mortes. Práticas pluralistas devem ser consideradas, incluindo a maior gama possível de indivíduos e comunidades no debate sobre seus próprios destinos como sujeitos de direitos.

\section{REFERÊNCIAS}

CANCLINI, Néstor Garcia. A Globalização imaginada. Tradução de Sérgio Molina. São Paulo: iluminuras, 2007.

CARVALHO, Lucas Borges. Caminhos (e descaminhos) do pluralismo jurídico no Brasil. In Pluralismo Jurídico: os novos caminhos da contemporaneidade. WOLKMER, Antônio Carlos, NETO, Francisco Q. Veras; LIXA, Ivone M. (orgs). São Paulo: Ed. Saraiva, 2013.

CLAVERO, Bartolomé. Estado Plurinacional - aproximação de um novo paradigma Constitucional Americano. In: Aprender desde o sul: novas constitucionalidades, pluralismo jurídico e plurinacionalidade - aprendendo desde o sul. BALDI, César Augusto (coordenador). Belo Horizonte: Forum, 2010.

GRIJALVA, Agustín. El Estado Plurinacional e Intercultural en la Constitución Ecuatoriana del. Disponível em http://repositorio.flacsoandes.edu.ec/ bitstream/10469/4170/1/RFLACSO-ED75-04-Grijalva.pdf. Acesso em 22 de fevereiro de 2020 .

FAJARDO, Raquel. Pluralismo Jurídico Y Jurisdicción Indígena em El horizonte del constitucionalismo pluralista. In: Aprender desde o sul: novas constitucionalidades, pluralismo jurídico e plurinacionalidade - aprendendo desde o sul. BALDI, César Augusto (coordenador). Belo Horizonte: Forum, 2010.

FAORO, Raymundo. Os donos do poder: formação do patronado político brasileiro. São Paulo: Globo, 2001.

FEATHERSTONE, Mike. Cultura de Consumo e Pós-modernismo. São Paulo: Studio Nobel,1990.

HOBSBAWM, Eric J. A era do capital: 1848-1875. 12a São Paulo: Paz e Terra, 2007.

MALISKA, Marcos Augusto. Pluralismo Jurídico e Direito Moderno: notas para pensar a racionalidade jurídica na modernidade. Curitiba: Juruá, 2009

MALL, Luiza Helena. Resenha: Pluralismo Jurídico: Fundamentos de uma nova cultura do Direito. Álter Agora, n. 2, 1992. 
NEVES, Marcelo. Do pluralismo jurídico à miscelânea social: o problema da falta de identidade da(s) esfera (s) de juridicidade na modernidade periférica e suas implicações na América Latina. Direito em debate, v.1, n.1, Unijuí, 1991.

QUIJANO, Aníbal. Colonialidade do poder, eurocentrismo e América Latina. In: A colonialidade do saber: eurocentrismo e ciências sociais. Perspectivas latino-americanas. Edgardo Lander (org). Coleccion Sur Sur, CLACSO, Ciudad Autónoma de Buenos Aires, Argentina. Setembro 2005. Pág. 227-229.

PINHO, José Antonio Gomes de. Reforma do Aparelho do Estado: Limites do Gerencialismo frente ao Patrimonialismo. O\&S. V.5. Nº 12, Maior/Agosto de 1998.

RÚBIO, David Sanchez. Encantos e Desencantos dos Direitos Humanos: de emancipações, libertações e dominações. Tradução de Ivone Fernandes Morcilho Lixa e Helena Henkin. Porto Alegre: Livraria do Advogado, 2014.

SANTOS, Boaventura de Sousa. O Direito dos oprimidos. São Paulo: Cortez Editora, 2014.

O Discurso e o Poder: ensaios sobre a sociologia da retórica jurídica Porto Alegre: Sérgio Fabris Editor, 1988.

WOLKMER, Antônio Carlos. Pluralismo Jurídico: fundamentos de uma nova cultura no direito. 4a ed. São Paulo: Saraiva, 2015. 